\title{
Cholinergic, But Not Dopaminergic or Noradrenergic, Enhancement Sharpens Visual Spatial Perception in Humans
}

\author{
[Caterina Gratton, ${ }^{1}{ }^{\circledR}$ Sahar Yousef, ${ }^{2,3}$ ¿Esther Aarts, ${ }^{4}$ Deanna L. Wallace, ${ }^{5}{ }^{\circledR}$ Mark D'Esposito, ${ }^{6}$ \\ and $\odot$ Michael A. Silver ${ }^{2,3,6}$ \\ ${ }^{1}$ Neurology Department, Washington University, St. Louis, Missouri 63110, ${ }^{2}$ School of Optometry, University of California, Berkeley, California 94720 , \\ ${ }^{3}$ Vision Science Graduate Group, University of California, Berkeley, California 94720, ${ }^{4}$ Donders Institute, Centre for Cognitive Neuroimaging, Radboud \\ University, Nijmegen $6525 \mathrm{EN}$, The Netherlands, ${ }^{5}$ Department of Neurosurgery, University of California, San Francisco, California 94122, and ${ }^{6} \mathrm{Helen}$ Wills \\ Neuroscience Institute, University of California, Berkeley, California 94720
}

The neuromodulator acetylcholine modulates spatial integration in visual cortex by altering the balance of inputs that generate neuronal receptive fields. These cholinergic effects may provide a neurobiological mechanism underlying the modulation of visual representations by visual spatial attention. However, the consequences of cholinergic enhancement on visuospatial perception in humans are unknown. We conducted two experiments to test whether enhancing cholinergic signaling selectively alters perceptual measures of visuospatial interactions in human subjects. In Experiment 1, a double-blind placebo-controlled pharmacology study, we measured how flanking distractors influenced detection of a small contrast decrement of a peripheral target, as a function of target-flanker distance. We found that cholinergic enhancement with the cholinesterase inhibitor donepezil improved target detection, and modeling suggested that this was mainly due to a narrowing of the extent of facilitatory perceptual spatial interactions. In Experiment 2, we tested whether these effects were selective to the cholinergic system or would also be observed following enhancements of related neuromodulators dopamine or norepinephrine. Unlike cholinergic enhancement, dopamine (bromocriptine) and norepinephrine (guanfacine) manipulations did not improve performance or systematically alter the spatial profile of perceptual interactions between targets and distractors. These findings reveal mechanisms by which cholinergic signaling influences visual spatial interactions in perception and improves processing of a visual target among distractors, effects that are notably similar to those of spatial selective attention.

Key words: acetylcholine; attention; dopamine; norepinephrine; pharmacology; visuospatial perception

Significance Statement

Acetylcholine influences how visual cortical neurons integrate signals across space, perhaps providing a neurobiological mechanism for the effects of visual selective attention. However, the influence of cholinergic enhancement on visuospatial perception remains unknown. Here we demonstrate that cholinergic enhancement improves detection of a target flanked by distractors, consistent with sharpened visuospatial perceptual representations. Furthermore, whereas most pharmacological studies focus on a single neurotransmitter, many neuromodulators can have related effects on cognition and perception. Thus, we also demonstrate that enhancing noradrenergic and dopaminergic systems does not systematically improve visuospatial perception or alter its tuning. Our results link visuospatial tuning effects of acetylcholine at the neuronal and perceptual levels and provide insights into the connection between cholinergic signaling and visual attention.

\section{Introduction}

Neuromodulators such as acetylcholine (ACh), dopamine (DA), and norepinephrine (NE) play important roles in spatial atten- tion and its influence on perception and sensory processing (for reviews, see Sarter et al., 2005; Bentley et al., 2011; Hasselmo and Sarter, 2011; Noudoost and Moore, 2011b; Thiele, 2013). In par- 
ticular, converging evidence from lesions, pharmacological studies, and direct measurements of cortical ACh release have demonstrated the importance of the cholinergic system in endogenous visual attention (Robbins et al., 1989; Muir et al., 1992; Passetti et al., 2000; Arnold et al., 2002; Bentley et al., 2004; Herrero et al., 2008; Rokem et al., 2010).

Physiologically, ACh alters the spatial properties of receptive fields (RFs) of visual cortical neurons, thereby changing how visual space is represented and how visual stimuli are segregated from one another. In primary visual cortex, application of ACh reduces the spread of excitatory responses to electrical stimulation in rat visual cortical slice recordings (Kimura et al., 1999) and decreases the optimal stimulus size for individual V1 neurons in marmosets (Roberts et al., 2005). In humans, systemic cholinergic enhancement decreases the spread of early visual cortical excitatory fMRI responses to a visual stimulus (Silver et al., 2008). These effects of ACh on spatial integration in visual cortex may be due to an increase in the strength of thalamocortical inputs relative to intracortical lateral connections (Gil et al., 1997; Disney et al., 2007, 2012; Giocomo and Hasselmo, 2007). Reweighting of input signals enhances the classical central RF of visual cortical neurons while decreasing influences from the extraclassical $\mathrm{RF}$, thereby decreasing the spatial extent of excitatory visual responses.

Notably, visual spatial attention also affects visual cortical RF size. These effects depend on eccentricity, and in macaque V1, attention reduces excitatory RF size for stimuli presented at eccentricities of 2-3 degrees of visual angle (Roberts et al., 2007), similar to the effects of ACh described above. Furthermore, spatial attention is known to affect the resolution of visual perception (for review, see Anton-Erxleben and Carrasco, 2013), and a cholinergically mediated reduction in visual RF size is consistent with an enhanced resolution of visuospatial representations. However, a link between the physiological effects of ACh on spatial integration of visual cortical responses and on human visual perception remains to be demonstrated.

In a previous study, we found that cholinergic enhancement with the cholinesterase inhibitor donepezil decreased behavioral measures of orientation-specific surround suppression in humans (Kosovicheva et al., 2012). One potential cause of this diminished visual surround suppression by ACh is a decrease in spatial interactions between the target and its suppressive surround, due to smaller visual excitatory RFs. Here, we directly tested the effects of ACh on the tuning of visuospatial perception in humans. We assessed visual tuning by systematically measuring thresholds for detecting a target flanked by distractors at different distances in a double-blind, placebo-controlled, crossover design.

Furthermore, although most pharmacological studies focus on a single neurotransmitter, many neuromodulator systems are simultaneously active and can have related effects on cognition and perception. In particular, the catecholamines DA and NE have been implicated in a variety of top-down control and attention-related processes (Arnsten and Li, 2005; Robbins and Arnsten, 2009), including spatial attention, working memory, and arousal (Aston-Jones and Cohen, 2005; Robbins and Arnsten, 2009; Noudoost and Moore, 2011a). Therefore, we examined whether dopaminergic and noradrenergic enhancement in humans would also influence visuospatial interactions in perception. Specifically, we administered either bromocriptine (a dopamine D2/D1 receptor agonist) or guanfacine (a noradrenergic $\alpha$-2a receptor agonist) and assessed performance on the same target detection task described above. Combining these studies allowed us to determine how enhancement of three distinct neurotransmitter systems affected visual perception and the visuospatial tuning of target-flanker interactions in humans.

\section{Materials and Methods}

General. Two separate behavioral pharmacology experiments in different participant groups with distinct drug manipulations (Experiment 1: donepezil and placebo; Experiment 2: bromocriptine, guanfacine, and placebo) are reported here. The same visual target detection task was completed by participants in both experiments.

Participants. Twenty-eight healthy young adults (14 females; average age $=23$ years, range $=19-34$ years) completed Experiment 1 , and 23 healthy young adults ( 11 females; average age $=23$ years, range $=19-37$ years) completed Experiment 2. An additional participant (Experiment 1 ) and 8 participants (Experiment 2 ) did not complete all of the required sessions.

All participants had normal or corrected-to-normal vision and were paid for their participation. Exclusion criteria for both experiments included a history of heart arrhythmia, neurological disorders, psychoactive medication, tobacco smoking, and pregnancy. Participants from Experiment 2 were also required to be right-handed native English speakers with normal color vision and were excluded if they did not meet (1) additional MRI screening criteria (had pacemakers, vascular disease, history of claustrophobia, or history of head trauma) or (2) additional exclusion criteria for the dopaminergic and noradrenergic medications. These included hypertension or hypotension (diastolic values $<60$ or $>90 \mathrm{mmHg}$, systolic values $<100$ or $>160 \mathrm{mmHg})$, low heart rate $(<50$ beats per minute), low or high body mass index $\left(<19 \mathrm{or}>30 \mathrm{~kg} / \mathrm{m}^{2}\right)$, or not meeting neurological assessment score cutoffs (a score of $>11$ on the Beck Depression Inventory or $>16$ errors on the National Adult Reading Test). Written informed consent was obtained from all participants, and both experiments were approved by the Committee for the Protection of Human Subjects at the University of California, Berkeley.

Experimental timeline. Experiments 1 and 2 both used double-blind, placebo-controlled, crossover designs (Fig. 1).

In Experiment 1 (Fig. 1A), participants completed five sessions on different days. Session 1 was used to familiarize participants with the task and with maintaining stable eye position at fixation (see description in Eye movements section). Participants then completed two pairs of two sessions: a refresher session ( 2 and 4 ) followed the next day by a pharmacological session ( 3 and 5 ) in which participants were administered either a donepezil ( $5 \mathrm{mg}$, an acetylcholinesterase inhibitor) or placebo pill. The refresher sessions served to equalize the amount of recent practice with the task that participants experienced before taking donepezil or placebo.

Pills were ingested $3 \mathrm{~h}$ before the start of the experiment to allow donepezil to reach peak plasma concentration (Rogers and Friedhoff, 1998). Pharmacological sessions 3 and 5 were separated by at least 2 weeks to ensure that donepezil was fully eliminated from the body (the half-life of donepezil is $\sim 80 \mathrm{~h}$ ) (Rogers and Friedhoff, 1998). Three or four task runs were completed in each of the five sessions. The task procedure was similar on all session days, but only data from the pharmacological sessions were analyzed.

In Experiment 2 (Fig. 1B), participants completed four sessions on different days. As in Experiment 1, each participant first completed a training session (Session 1: one practice run of low task difficulty and three training runs at psychophysical threshold) to become familiar with the task and with maintaining fixation. The other three sessions consisted of administration of bromocriptine ( $1.25 \mathrm{mg}$, a dopamine D2/D1 receptor agonist, with $\sim 100$-fold stronger binding affinity for D2 receptors (Gerlach et al., 2003)), guanfacine ( $1 \mathrm{mg}$, an $\alpha$-2a receptor agonist adrenoceptor agonist), or a placebo pill. For each pharmacological session, a refresher period was conducted immediately after pill ingestion and before the drugs had time to reach high plasma concentrations (see below). During the refresher period, participants completed two practice runs on the task. This was followed by extensive behavioral testing and MRI for a separate project not reported here. Behavioral data for this study were then collected $\sim 4-4.5 \mathrm{~h}$ after pill ingestion (peak plasma concentration for bromocriptine occurs $\sim 2.5 \mathrm{~h}$ after ingestion, with a half-life of $\sim 7 \mathrm{~h}$ 


\section{A Experiment 1 : donepezil $(D)$ and placebo $(P)$}

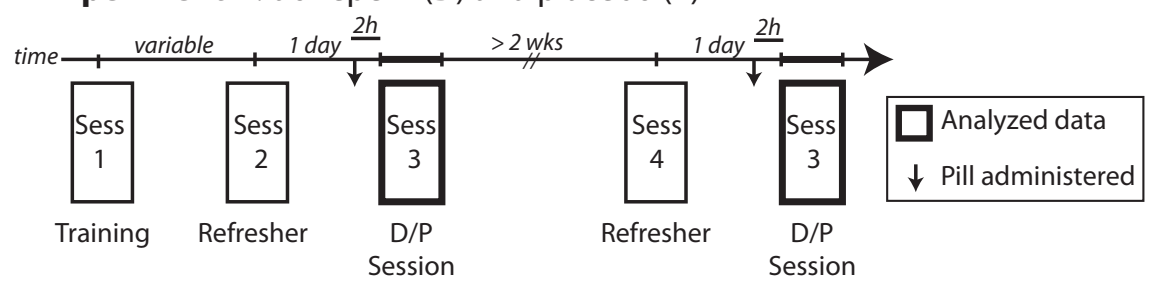

B Experiment 2: bromocriptine (B), guanfacine $(G)$, and placebo $(G)$

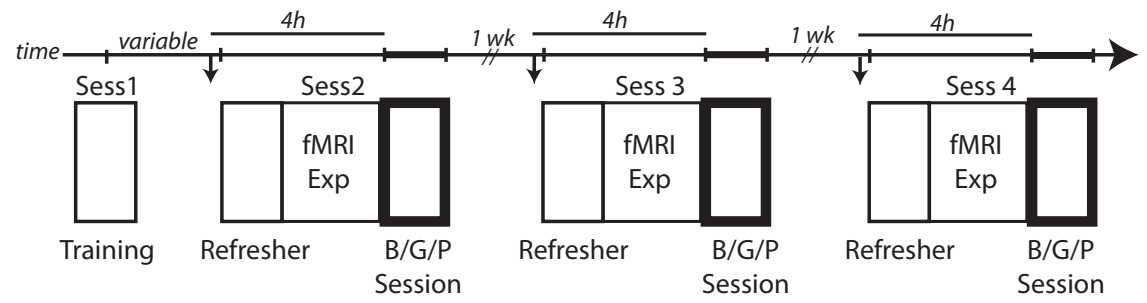

Figure 1. Experimental timeline. $A$, Experiment 1 contrasted the effects of cholinergic enhancement with donepezil (D) against placebo (P) in a within-subject, double-blind, placebo-controlled experiment with five separate sessions, including two refresher sessions to refamiliarize subjects with the task and to equate recent experience with the task for $D$ and $P$ pharmacological sessions. $B$, Experiment 2 examined the effects of dopaminergic enhancement (with bromocriptine [B]) and noradrenergic enhancement (with guanfacine [G]) in the same visual target detection task. Experiment 2 was also a within-subject, double-blind, placebocontrolled experiment and contained four experimental sessions, with a refresher period at the start of each pharmacological session, well before the administered drugs had any significant effects.

(Deleu et al., 2002), and peak concentration for guanfacine occurs 1-4 $\mathrm{h}$ after ingestion, with a half-life of $\sim 17 \mathrm{~h}$ (Mosqueda-Garcia, 1990)). Two or three task runs were completed in each of the pharmacological sessions, and 1 week separated each of the three sessions.

In addition, a number of self-report and physiological measures were collected to assess potential side effects associated with guanfacine and bromocriptine. Measurements were made at several time points in each session, including at the start of each session before drug intake (Time 1) and immediately before behavioral testing (Time 3; Time 2 was taken immediately before MRI). Self-report measures included visual analog scales of anxiety, mood (happiness, sadness), nausea, dizziness, and fatigue (fatigue, drowsiness, jitteriness), as well as the State and Trait Anxiety Inventory. Physiological measures included heart rate and systolic and diastolic blood pressure. The differences between predrug and testing (Time 3 - Time 1) were compared between the placebo and drug sessions using two-tailed paired $t$ tests, FDR correcting for multiple comparisons across tests.

Visual stimuli and task. Participants performed a contrast decrement task on a peripheral (eccentricity of 3 degrees of visual angle) target (25\% contrast, defined as the SD of the luminance; see Fig. 2, inset) that was flanked by high-contrast distractors ( $75 \%$ contrast; see Fig. 2 , inset) while maintaining central fixation. Targets and flankers consisted of the same pair of spatially overlapping grayscale face images that were matched for average luminance and presented on an average luminance gray background. These unusual stimuli were selected to allow these data to be compared with other experiments on feature-based attention (not reported here).

Each trial began with $400 \mathrm{~ms}$ of presentation of an arrow-shaped cue at fixation that indicated the location of the target (either the left or right quadrant of the upper visual field) with $100 \%$ validity. This was followed by a $200 \mathrm{~ms}$ cue-stimulus interval and then $2.16 \mathrm{~s}$ of a stimulus display that flashed at a frequency of $2.78 \mathrm{~Hz}$ ( (ix cycles of $250 \mathrm{~ms}$ on, $110 \mathrm{~ms}$ off).

The experimental manipulation was the distance between target and flankers, which was pseudorandomly varied on each trial within a range of 0.2-2.0 degrees of visual angle (stimulus edge-to-edge distance, or 1.2-3.0 degrees center-to-center distance). The positions of the target and flankers were outlined with thin white squares on each trial to decrease spatial uncertainty. On half of the trials, one of the five $250 \mathrm{~ms}$ stimulus presentations (excluding the first cycle) con- tained a small contrast decrement presented for the entire $250 \mathrm{~ms}$ duration. Because the stimulus presentation that contained the contrast decrement was randomly selected on each trial (for the $50 \%$ of trials that had a contrast decrement), subjects needed to continuously maintain covert attention at the target location.

At the end of each trial, subjects responded using one of two buttons to indicate whether or not there had been a contrast decrement on that trial. The magnitude of the contrast decrement was adaptively varied to determine the threshold for $75 \%$ accuracy on the task and was calculated using the Bayesian QUEST staircase procedure (Watson and Pelli, 1983) (http:// psych.nyu.edu/pelli/software.html\#quest) for each target-flanker distance.

Subjects did not have any time limit to make their responses, and they were encouraged to respond as accurately as possible. No contrast decrements ever occurred in the flankers. Auditory feedback was given on every trial, and a visual summary of task performance was provided at the end of each 50 trial block to encourage participants to stay engaged in the task.

Procedure. Each session began with a short practice run (50 trials, $\sim 5 \mathrm{~min}$ ) at a constant contrast decrement of $50 \%$. This was followed by 3 or 4 runs of the task. For each run, 50 trials from each target-flanker distance $(0.2,0.8 .1 .4$, and 2.0 degrees of visual angle; edge-to-edge) were pseudo-randomly intermixed (200 trials total). There were 10 additional trials at the beginning of each run that were discarded to prevent the psychophysical staircase from being overly influenced by the subject's initial responses. Each run took $\sim 15 \mathrm{~min}$, with breaks and performance summaries provided every 50 trials ( $\sim 5 \mathrm{~min})$. A single experimental session took $1-1.5 \mathrm{~h}$.

The experiment was coded and thresholds were calculated using functions from the Psychophysics Toolbox (http://psychtoolbox.org) (Brainard, 1997; Pelli, 1997; Kleiner et al., 2007). All experiments were conducted in darkened rooms with a chin rest to stabilize head position. Viewing distance was $40 \mathrm{~cm}$ (Experiment 1) or $42 \mathrm{~cm}$ (Experiment 2) from the display screen.

Eye movements. The need to maintain fixation throughout the task was strongly emphasized to participants in their first training session and again in the instructions preceding each run. To train participants to maintain fixation, an experimenter monitored eye movements with an infrared camera placed in front of one of the participant's eyes during the first training session. Each participant completed a practice block of trials, and immediate auditory feedback was provided whenever fixation was broken. By the end of the practice block, participants were able to maintain stable fixation during the task. We have previously used similar training procedures and evaluation of fixation stability for similar covert attention tasks and have shown that eye movements are infrequent and do not differ for donepezil and placebo $(\sim 0.5 \%$ of trials) (Silver et al., 2008; Rokem et al., 2010) or for bromocriptine and placebo ( $\sim 0.3 \%$ of trials) (Rokem et al., 2012).

Analysis. For both experiments, analyses were conducted on the median of the threshold estimates from each run from each participant. Initial analyses were conducted using a repeated-measures ANOVA with factors of pill type (donepezil and placebo for Experiment 1, bromocriptine and placebo, or guanfacine and placebo for Experiment 2) and target-flanker distance $(0.2,0.8,1.4$, and 2.0 degrees $)$. Differences between drug effects in Experiment 1 and 2 were compared using a similar mixedmodel ANOVA with an additional between-subjects factor of experiment (Experiment 1 or 2). Post hoc $t$ tests were used to compare drug and placebo results at specific target-flanker distances. For ease of visualization, behavioral performance is displayed in figures in units of sensitivity 


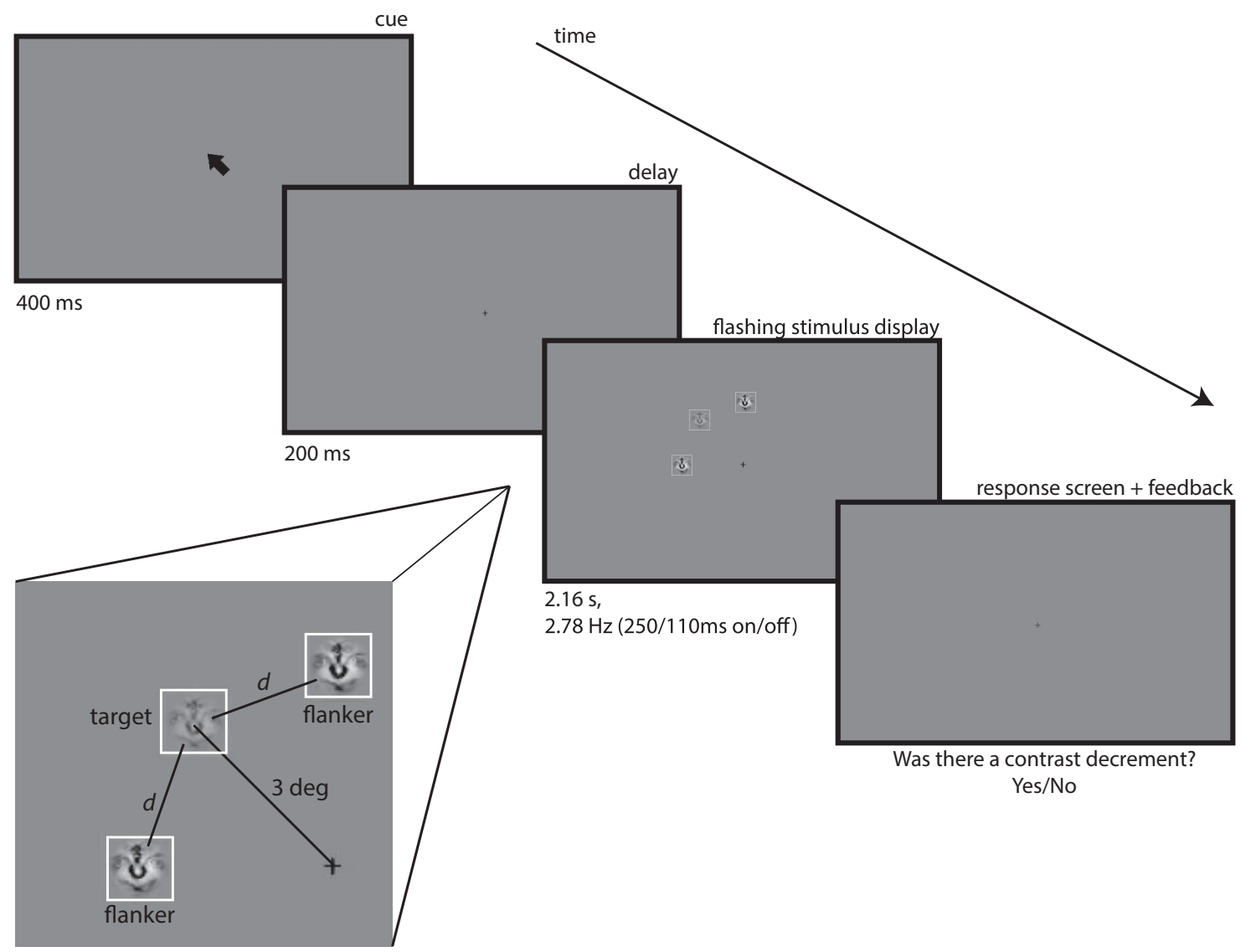

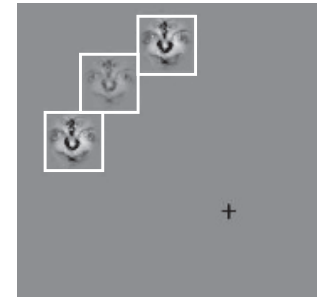

$d=0.2 \mathrm{deg}$

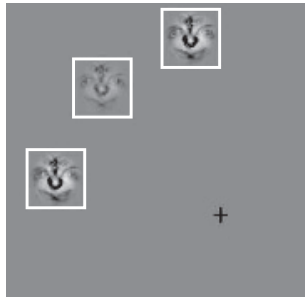

$d=0.8 \mathrm{deg}$

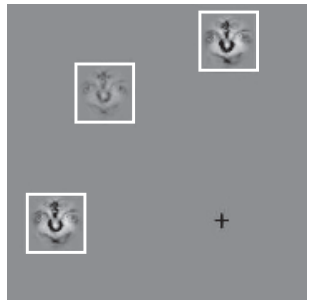

$d=1.4 \mathrm{deg}$

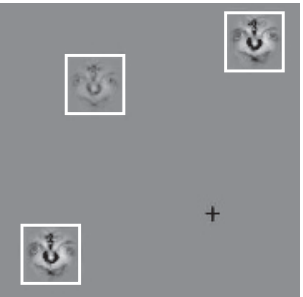

$d=2.0 \mathrm{deg}$

Figure 2. Task design. Each trial of the task began with a cue pointing to either the left or right top quadrant that indicated the location of the subsequent stimulus display, consisting of a low-contrast target flanked by high-contrast distractors (shown enlarged in inset, with white borders thickened for visualization). The critical manipulation was the distance between target and flankers, which varied between 0.2 and 2.0 degrees of visual angle. The participants' task was to determine whether a slight contrast decrement occurred in the target at some point during the display period ( $50 \%$ probability). The magnitude of the contrast decrement was adaptively varied from trial to trial to determine the threshold for $75 \%$ target detection accuracy.

(1-contrast threshold for $75 \%$ accuracy), although statistical analyses were conducted on raw threshold values.

A second set of analyses was based on previously reported spatial profiles of target-flanker interactions in visual perception (Polat and Sagi, 1993; Müller et al., 2005a) and involved modeling the data with a Difference of Gaussians (DoG) profile, separately for each drug and placebo session. Unlike the analysis described above, which treats each distance as an independent condition, this procedure includes an explicit model of the function relating contrast decrement detection thresholds to targetflanker distance.

We included the following parameters in our model: the amplitude and SD (width) of a broadly tuned Gaussian that reflects long-range facilitatory interactions between the target and flankers (Gaussian 1, or G1; see Fig. $4 A$ ) and the amplitude and SD of a more narrowly tuned Gaussian that reflects shorter-range suppressive target-flanker perceptual interactions (Gaussian 2, or G2; see Fig. 4A).

Data were demeaned before modeling. Model fitting was performed using the fmincon function in MATLAB (R2011b; The MathWorks), with added constraints that Gaussian 1 had lower am- plitude and greater width than Gaussian 2 and that all values had to be positive and $<2$ (despite the similar bounding values, the units of measurement for amplitude and SD of the Gaussians were contrast decrement detection threshold and target-flanker distance in degrees of visual angle, respectively). This fitting procedure merely translates the original measurements of contrast threshold at each targetflanker distance into Gaussian parameters, as only four target-flanker distances were used to fit the four parameters. However, the constraints on parameter values prevent excessive overfitting, and our main experimental question of interest is the drug effect on each of the Gaussian parameters, not the parameter values themselves.

Initial values for the fitting algorithm were selected by iterating through a range of possible initial values for each parameter $(0-1$ in steps of 0.01 and $1-2$ in steps of 0.1 ; at this stage, each parameter was individually fit while other parameters were kept constant at a value of 1) and then selecting the initial value for each parameter that produced the lowest error (sum of squared errors) for the fit of each individual experimental session. This sampling scheme and range were used to select initial parameter values that minimized the frequency of border solu- 
tions. This procedure is not biased for any individual condition, as it was conducted independently for all placebo and drug session data.

The computed model parameters were entered into a repeatedmeasures ANOVA with factors of parameter (amplitude and width of Gaussian 1, amplitude and width of Gaussian 2) and pill type (donepezil and placebo for Experiment 1, bromocriptine and placebo or guanfacine and placebo for Experiment 2). Differences in drug effects between Experiments 1 and 2 were assessed using a mixed-model ANOVA with the additional between-subjects factor of experiment. In the figures, the drug effects on each parameter are displayed as contrast indices: (drug placebo $) /($ drug + placebo $)$. A positive contrast index indicates that the parameter (width or amplitude) increased in magnitude with the drug, whereas a negative contrast index indicates that the value of the parameter decreased with the drug.

All ANOVAs were analyzed using the repeated-measures ANOVA function in SPSS (version 22). If Mauchly's test indicated a significant deviation from sphericity, $F$ statistic values were corrected for sphericity using the Huynh-Feldt procedure; and in these cases, $p$ values are reported as $p(\mathrm{HF})$. All post hoc $t$ tests were FDR-corrected for multiple comparisons across conditions (i.e., the number of distances tested) using the p.adjust function with method FDR in R (version 3.0.2), and the resulting $p$ values are reported as $p(\mathrm{FDR})$.

\section{Results}

\section{Experiment 1}

In Experiment 1, we examined the effects of increasing cholinergic signaling with donepezil on contrast decrement detection of targets flanked by distractors at different distances (Fig. 2).

\section{Effects of donepezil on target-flanker interactions in visual perception}

Figure 3 shows the effects of target-flanker distance on contrast decrement detection. Both donepezil and placebo sessions generated a characteristic Difference of Gaussians (DoG) spatial profile of performance: sensitivity was lowest when flankers were closest to the target, and performance improved at greater distances, eventually plateauing at large distances.

We examined the influence of target-flanker distance on performance using an ANOVA with within-subject factors of target-flanker distance $(0.2,0.8,1.4$, and 2.0 degrees) and pill type (donepezil or placebo). We found a significant main effect of distance $\left(F_{(3,81)}=10.0, p<0.001\right)$, indicating that target detection was influenced by the distance between the target and flanker. In addition, there was a significant main effect of drug $\left(F_{(1,27)}=4.64, p<0.05\right)$, reflecting better overall performance on donepezil than placebo. Post hoc $t$ tests suggested that the effects of donepezil were particularly pronounced at intermediate target-flanker distances (distance 0.8: $t_{(27)}=3.20, p<0.005$, $p(\mathrm{FDR})=0.01$; all other distances $p(\mathrm{FDR})>0.23)$. However, the drug by distance interaction term in the ANOVA did not reach significance $\left(F_{(3,81)}=1.38\right)$.

\section{Modeling effects of donepezil on facilitatory and suppressive} target-flanker interactions

To quantify the effects of donepezil on the spatial profile of flanker interference, we fit the data from each individual session with a DoG model. The model contained four free parameters: the amplitude (A1) and width (S1) of a positively signed Gaussian to model facilitatory effects of flankers on target detection, and the amplitude (A2) and width (S2) of a negative (suppressive) Gaussian (Fig. 4A; for a more extensive description of the fitting procedure, see Materials and Methods).

A repeated-measures ANOVA with factors of parameter (A1, S1, A2, S2) and pill type (donepezil, placebo) showed a significant interaction between parameter and pill type $\left(F_{(3,81)}=4.87, p<\right.$ $0.005, p(\mathrm{HF})=0.01$; Figure $4 B)$. Post hoc $t$ tests revealed that the
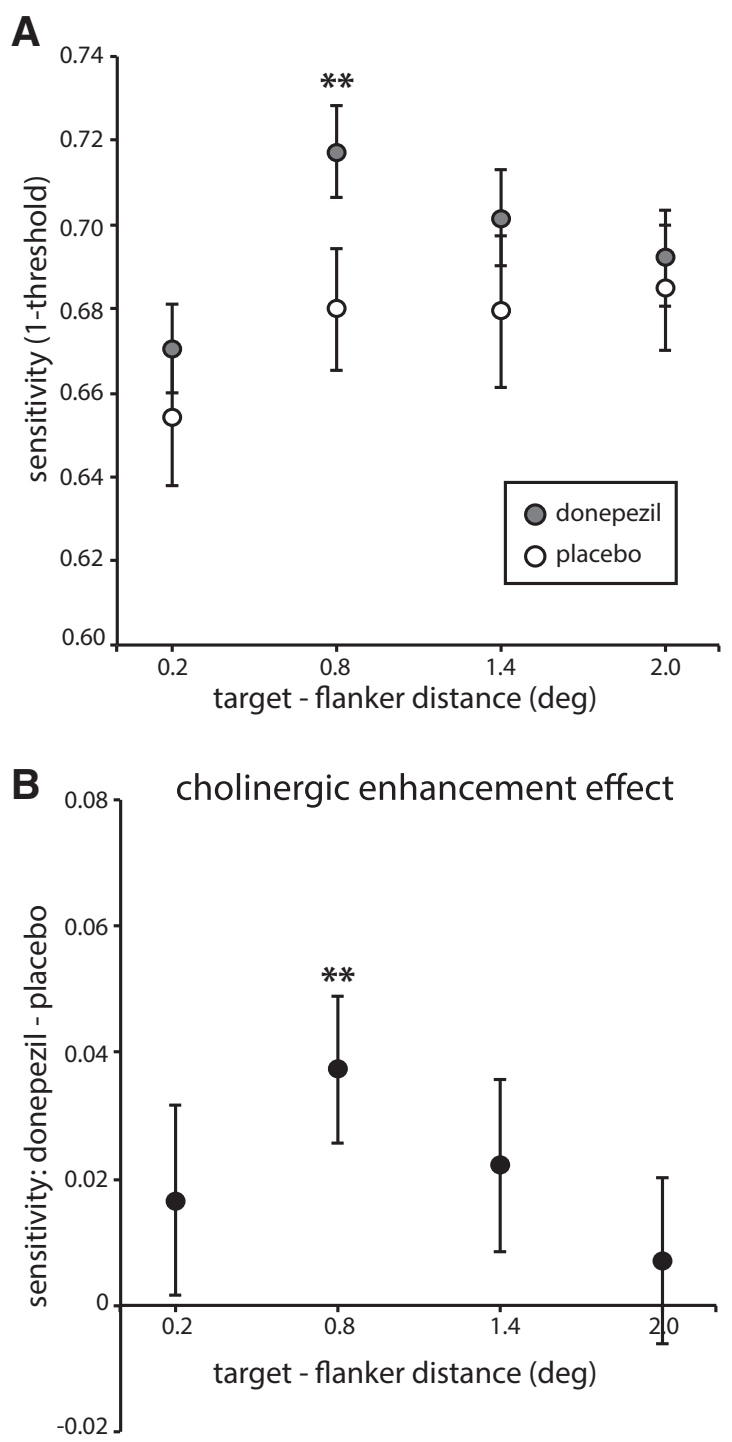

Figure 3. Experiment 1. Effects of donepezil on target-flanker interactions in visual perception. $A$, The effect of target-flanker distance on sensitivity of contrast decrement detection after taking a donepezil or a placebo pill. $\boldsymbol{B}$, The difference between sensitivity for donepezil and placebo conditions at different target-flanker distances. Compared with placebo, donepezil increased sensitivity, especially at intermediate ( 0.8 degree) distances. Error bars indicate SEM $(\boldsymbol{A})$ across participants and $(\boldsymbol{B})$ across participants for the donepezil-placebo difference. ${ }^{* *} p<0.01$.

interaction was primarily driven by a significant decrease in the width of the facilitatory Gaussian $\left(S 1 ; t_{(27)}=3.03, p<0.01\right.$; $p(\mathrm{FDR})=0.02)$, consistent with a sharpened tuning of facilitatory target-flanker interactions in visuospatial perception following cholinergic enhancement. No other parameters differed significantly across the two experimental sessions (all $p>0.10$ ).

\section{Experiment 2}

Experiment 2 used the same behavioral paradigm and modeling approach as Experiment 1 to examine how systemically increasing DA and NE levels (through bromocriptine and guanfacine administration, respectively) influenced target detection and the spatial profile of target-flanker interactions.

\section{Effects of bromocriptine and guanfacine on}

\section{target-flanker interactions}

Placebo. Contrast decrement detection thresholds as a function of target-flanker distance in Experiment 2 are shown in Figure $5 \mathrm{~A}$. 

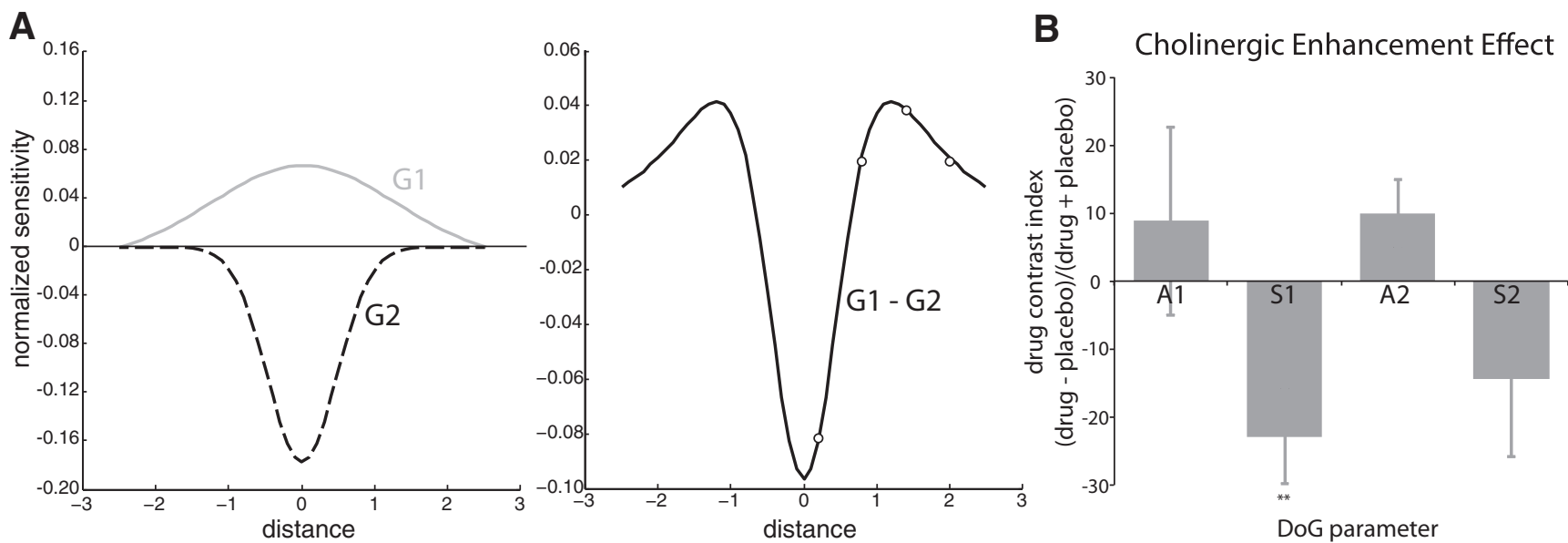

Figure 4. Experiment 1. Modeling effects of donepezil on facilitatory and suppressive target-flanker interactions. A, A DoG curve (G1-G2, right) was fit to the data with four parameters: the amplitude (A1) and width (S1) of the broad facilitatory Gaussian (G1, gray line) and the amplitude (A2) and width (S2) of the narrower suppressive Gaussian (G2, black dashed line) separately for placebo and donepezil sessions. $\boldsymbol{B}$, The cholinergic enhancement effect on each parameter is displayed as a contrast index (drug - placebo/drug + placebo). Positive values indicate that the drug increased amplitude/width, and negative values indicate that the drug decreased amplitude/width for each Gaussian. Compared with placebo, donepezil significantly decreased the spatial extent of the facilitatory Gaussian $(S 1){ }^{* *} p<0.01$.

Performance in the placebo session showed a characteristic DoG shape across distances, with lowest sensitivity for target detection when flankers were closest to the target and improving (and then plateauing) sensitivity for further distances. A between-subjects ANOVA comparing thresholds from placebo sessions in Experiments 1 and 2 showed no overall difference between the two (main effect of experiment: $F_{(1,49)}=0.17$; interaction between distance and experiment: $\left.F_{(3,147)}=0.53\right)$. This indicates that, although the experimental procedures differed slightly between the two experiments (see Materials and Methods), our measurements of psychophysical thresholds and spatial interactions were robust to these differences.

Bromocriptine. A repeated-measures ANOVA comparing thresholds in bromocriptine versus placebo sessions indicated a significant interaction between drug and distance $\left(F_{(3,66)}=3.35\right.$, $p<0.03, p(\mathrm{HF})=0.03)$ but no main effect of drug $\left(F_{(1,22)}=\right.$ 0.14). Examination of the drug effects at each distance (Fig. $5 B$ ) suggests that the drug $X$ distance interaction was driven by decreased sensitivity at intermediate distances and a slight increase in sensitivity at close and very far distances. However, individual post hoc $t$ tests did not result in significant drug effects at any target-flanker distance (all p $[\mathrm{FDR}]>0.26$ ).

Guanfacine. A repeated-measures ANOVA comparing guanfacine to placebo resulted in a marginally significant main effect of drug $\left(F_{(1,22)}=3.16, p=0.09\right)$, with participants exhibiting a trend toward overall lower sensitivity on guanfacine. No other main effects or interactions were significant (Fig. 5C).

Self-report and physiological measures

We examined possible effects of bromocriptine and guanfacine on a number of physiological and self-report measures (Table 1), using paired $t$ tests to compare the change across time points for placebo versus drug sessions. There were no significant differences between bromocriptine and placebo or between guanfacine and placebo for any measure after correcting for multiple comparisons. Thus, it seems unlikely that systemic physiological effects of guanfacine or bromocriptine (e.g., drowsiness, dizziness) strongly affected either performance in our visuospatial task or perceptual tuning.

\section{Comparison with Experiment 1}

We directly compared the results of Experiments 1 and 2 by adding a between-subject factor of Experiment to each ANOVA. For bromocriptine compared with donepezil, this analysis identified a significant interaction of pill type, distance, and experiment $\left(F_{(3,147)}=4.68, p<0.005\right)$. This demonstrates that donepezil and bromocriptine have significantly different effects on the spatial profile of target-flanker interactions. No other interactions were significant.

For the comparison of guanfacine to donepezil, there was a pill type $\times$ experiment interaction $\left(F_{(1,49)}=7.02, p<0.02\right.$, $\mathrm{p}[\mathrm{HF}]<0.02)$, with a weak trend for the three-way pill type $X$ distance $\times$ experiment interaction $\left(F_{(3,147)}=2.05, p=0.11\right)$. No other interactions were significant. Thus, donepezil and guanfacine have significantly different effects on target detection that weakly interact with the distance between targets and flankers.

\section{Modeling effects of bromocriptine and guanfacine on facilitatory and suppressive target-flanker interactions}

As in Experiment 1, the specific effects of bromocriptine or guanfacine on the spatial profile of target-flanker interactions were examined with a DoG model (Fig. 6). An ANOVA comparing bromocriptine and placebo for the DoG parameters (A1, S1, A2, S2) showed no significant effects of pill type or interactions (all $p>0.44)$. Similarly, there were no significant effects of pill type or interactions in an ANOVA comparing guanfacine and placebo (all $p>0.58$ ). These findings indicate that, for both DA and NE, pharmacological enhancement of signaling did not alter either facilitatory or suppressive interactions between targets and flankers.

\section{Comparison with Experiment 1}

We compared model parameter values directly across experiments with an ANOVA that had an additional between-subject factor of experiment (Experiment 1 or 2). For both bromocriptine versus donepezil $\left(F_{(3,147)}=4.54, p<0.01\right)$ and guanfacine versus donepezil $\left(F_{(3,147)}=3.11, p=0.028\right)$, there was a significant three-way interaction of pill type, parameter, and experiment. These interactions indicate that cholinergic enhancement 
A

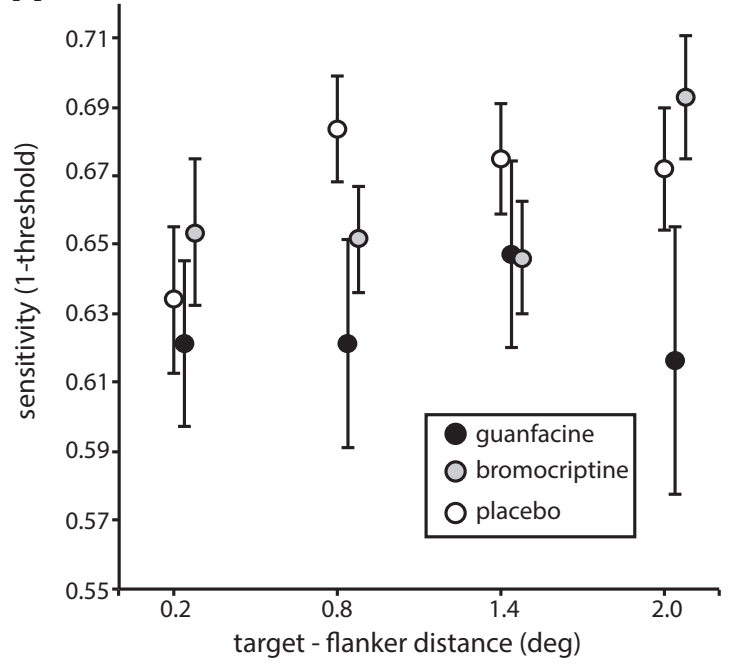

B
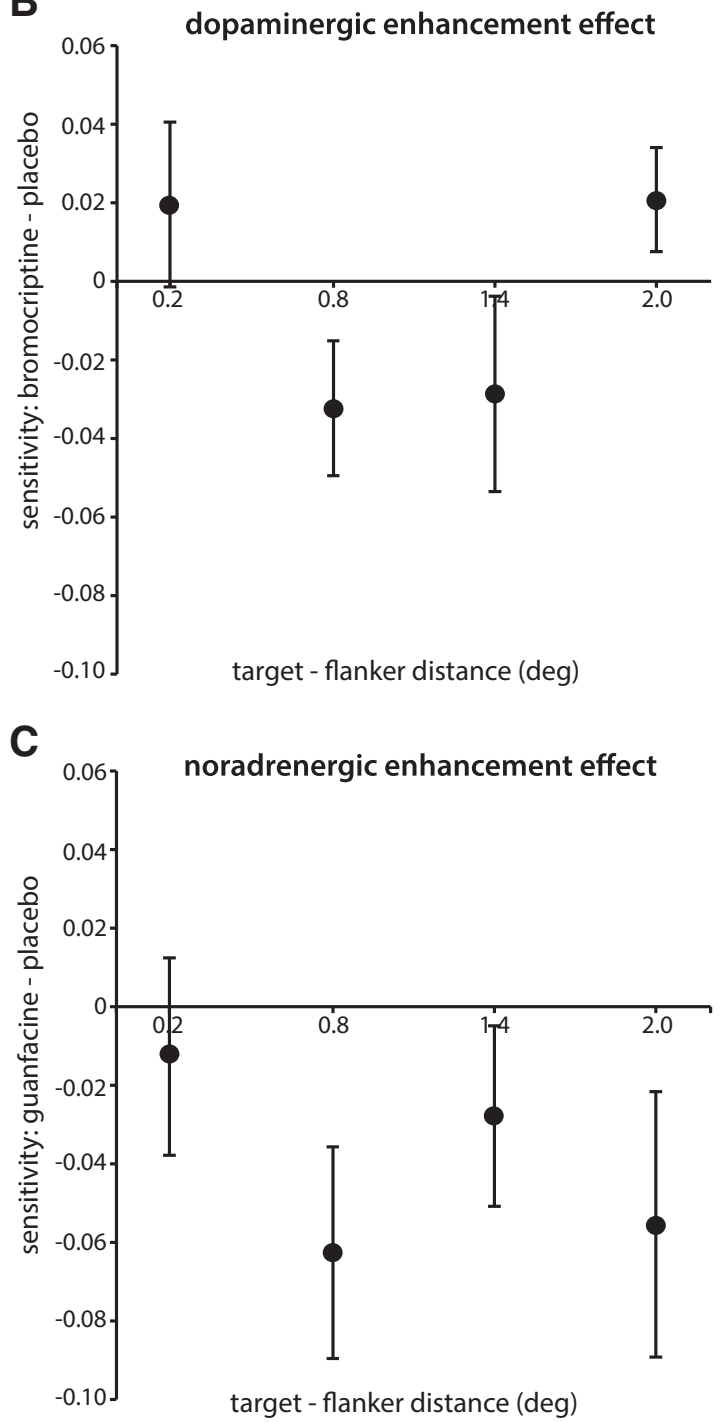

Figure 5. Experiment 2. Effects of bromocriptine and guanfacine on target-flanker interactions. $\boldsymbol{A}$, The effect of target-flanker distance on sensitivity of contrast decrement detection after taking placebo (white circles), bromocriptine (light gray), or guanfacine (dark gray). Data points have been slightly offset from one another to facilitate visualization, but target-flanker distances were the same in all drug conditions. $\boldsymbol{B}$, Paired differences between bromocriptine and placebo sessions. Bromocriptine weakly modulated target-flanker had a significantly different influence on the spatial profile of target-flanker interactions compared with either DA or NE enhancement, as described by the model parameters. No other interactions of drug or experiment were significant.

Placebo. Finally, analysis of parameter estimates revealed no significant interactions between the placebo data from Experiment 1 and the placebo data from Experiment $2\left(F_{(3,147)}=0.75\right)$. This provides further evidence that placebo data, and therefore the experimental procedures, were comparable for Experiments 1 and 2 .

\section{Discussion}

We have found that cholinergic enhancement with donepezil improved performance in a task requiring sustained attention to a target with flanking distractors, particularly at intermediate target-flanker distances. Modeling showed that donepezil decreased the width of facilitatory target-flanker interactions, corresponding to sharpened spatial tuning. In contrast, neither bromocriptine nor guanfacine systematically improved performance or affected the spatial tuning of perception.

\section{Relationship between cholinergic effects on visuospatial tuning of behavior and neuronal RFs}

What is the relationship between the perceptual effects of ACh that we observed and its physiological effects in early visual cortex? Neuronal RFs in V1 have three components: (1) central excitation driven by thalamocortical inputs, (2) a "near" surround that is driven primarily by local horizontal connections and can be excitatory or inhibitory, depending on stimulus properties such as contrast and orientation, and (3) an extensive "far" inhibitory surround driven mainly by feedback connections (Angelucci and Bressloff, 2006; Nurminen and Angelucci, 2014). Thus, for single neuron RFs, the spatial tuning of inhibition is broader than that of excitation.

ACh has differential actions on these inputs to visual cortical neurons, strengthening thalamocortical connections relative to lateral connections (Gil et al., 1997; Disney et al., 2007, 2012; Giocomo and Hasselmo, 2007). Given that RFs of excitatory thalamic inputs to cortex are smaller than those from V1 intracortical connections, a cholinergically mediated enhancement of feedforward processing is consistent with a reduction in excitatory RF size in visual cortex. Indeed, increasing cholinergic signaling reduces excitatory RF size of marmoset V1 neurons (Roberts et al., 2005) and decreases the spatial extent of excitatory visual responses in human visual cortex, as measured with fMRI (Silver et al., 2008). Our finding that cholinergic enhancement reduces the extent of facilitatory spatial interactions in perception is therefore conceptually consistent with the fact that ACh decreases excitatory RF size in visual cortex.

However, unlike individual visual cortical neurons, the spatial profile of target-flanker interactions in our perceptual task is characterized by poorest performance at short target-flanker distances and best performance at intermediate distances, consistent with broadly tuned facilitation and narrowly tuned suppression (Fig. 4A). This pattern has also been observed for collinear oriented Gabor patches (Polat and Sagi, 1993), circular targets flanked by circular stimuli (Yu and Levi, 1997), and letter stimuli (Müller et al., 2005a).

$\leftarrow$

interactions at different distances, tending to decrease sensitivity at intermediate distances C, Paired differences between guanfacine and placebo sessions. Guanfacine had no significant effect on target detection, although participants showed a trend toward impaired overall performance. 
Table 1. Physiological and self-report measures ${ }^{a}$

\begin{tabular}{|c|c|c|c|c|c|c|c|c|}
\hline & \multicolumn{2}{|l|}{ Placebo (P) } & \multicolumn{2}{|c|}{ Bromocriptine (B) } & \multicolumn{2}{|c|}{ Guanfacine (G) } & \multicolumn{2}{|c|}{$\begin{array}{l}t \text { test } p \text { value, } \\
\text { Time } 3-\text { Time } 1\end{array}$} \\
\hline Heart rate & $66.3(10.7)$ & $66.0(11.5)$ & $69.7(13.0)$ & $69.2(11.5)$ & $70.2(13.6)$ & $68.4(9.6)$ & n.s. & n.s. \\
\hline Blood pressure, diastolic & $68.9(7.2)$ & $71.3(10.2)$ & $66.7(8.1)$ & $68.1(9.8)$ & $68.6(9.6)$ & $68.8(9.0)$ & n.s. & n.s. \\
\hline VAS, anxious & $1.4(1.7)$ & $1.3(1.7)$ & $1.4(1.4)$ & $1.1(1.2)$ & $1.5(1.4)$ & $0.8(1.1)$ & n.s. & n.s. \\
\hline VAS, happy & $6.3(1.4)$ & $6.2(1.7)$ & $6.2(1.5)$ & $6.1(1.8)$ & $6.3(1.3)$ & $6.4(1.4)$ & n.s. & n.s. \\
\hline VAS, drowsy & $2.1(1.8)$ & $2.0(1.9)$ & $1.9(1.8)$ & $2.3(2.1)$ & $2.3(2.0)$ & $2.5(2.4)$ & n.s. & n.s. \\
\hline VAS, jittery & $0.7(0.8)$ & $1.0(1.3)$ & $1.1(1.4)$ & $1.1(1.2)$ & $1.0(1.2)$ & $0.8(1.3)$ & n.s. & n.s. \\
\hline VAS, fatigued & $2.5(2.0)$ & $2.5(2.0)$ & $1.9(1.5)$ & $2.8(2.3)$ & $2.3(1.8)$ & $2.6(2.5)$ & n.s. & n.s. \\
\hline VAS, dizzy & $0.7(0.8)$ & $1.1(1.4)$ & $0.6(0.8)$ & $1.3(1.6)$ & $0.7(1.0)$ & $0.8(1.4)$ & n.s. & n.s. \\
\hline State anxiety & $28.9(7.7)$ & $28.3(5.8)$ & $29.9(6.0)$ & $29.0(7.1)$ & $28.4(5.3)$ & $27.8(5.4)$ & n.s. & n.s. \\
\hline
\end{tabular}

${ }^{a}$ Comparison of the change in physiological (heart rate and blood pressure) or self-report (anxiety, mood, nausea, dizziness, and fatigue) measures collected in Experiment 2, after ingesting drug (guanfacine or bromocriptine) versus placebo No measure showed a significant drug effect. Values represent mean (SD). Time 1 is before drug intake; Time 3 is after drug intake, preceding behavioral testing. VAS, Visual analog scale. State anxiety was measured using the State and Trait Anxiety Inventory (STAI). n.S., Not significant ( $p>0.05$, paired two-tailed $t$ test, FDR-corrected for multiple comparisons).

This apparent discrepancy between spatial profiles in perception and neuronal RFs can be explained by the observation that contrast discrimination performance is related to the slope of the neural contrast response function (CRF), rather than the absolute magnitude of neural responses that are typically used to characterize neuronal RFs (Geisler and Albrecht, 1997). In our task, a higher CRF slope would be associated with better behavioral contrast discrimination of the contrast decrement target, relative to preceding/subsequent contrasts.

Given that neural CRFs saturate at higher stimulus contrasts, a lower firing rate can therefore improve contrast discrimination. Accordingly, the addition of nearby flanking stimuli (assumed to be within the central excitatory portion of the RFs of neurons mediating task performance) impairs behavioral contrast discrimination (Yu and Levi, 1997), presumably by shifting responses to a more saturated portion of the CRF. On the other hand, flankers placed at a distance corresponding to the presumed inhibitory RF surround reduce neuronal response amplitude but improve behavioral contrast discrimination (Yu and Levi, 1997), presumably by shifting neurons to the part of the CRF that has higher slope.

Relatedly, increasing the size of a grating increases fMRI response amplitudes in human visual cortex while impairing contrast discrimination of a small target overlaid on the grating when the grating is relatively small (and presumed to correspond to the central excitatory part of the RFs of neurons mediating task performance), but the opposite pattern of results is obtained when the grating is larger (Nurminen et al., 2009). Thus, while single neurons have narrow excitatory RFs and broad inhibitory RFs, tuning in perceptual contrast discrimination follows the opposite pattern, with narrow suppressive and broad facilitatory effects, consistent with our modeling results (Fig. 4A).

In this framework, a reduction in the spatial extent of facilitatory interactions in contrast decrement detection following donepezil administration is consistent with smaller excitatory neuronal RF size. Specifically, ACh shrinks excitatory RFs, thereby increasing the likelihood of flankers falling in the inhibitory surround of a given neuron's RF. This, in turn, results in improved contrast decrement

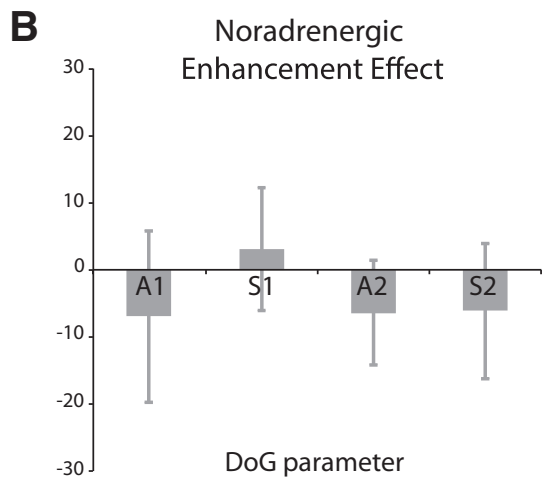

Dopaminergic Enhancement Effect

DoG parameter

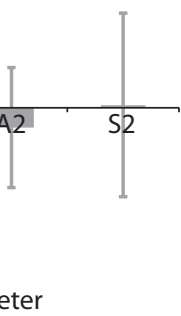

$-30$ .

Figure 6. Experiment 2. Modeling effects of bromocriptine and guanfacine on facilitatory and suppressive target-flanker interactions. Drug effects on the Gaussian parameter values for bromocriptine and placebo $(\boldsymbol{A})$ and guanfacine and placebo $(\boldsymbol{B})$ sessions from Experiment 2. Unlike the effects of cholinergic enhancement (Fig. 4B), no significant differences were seen for any parameters for either bromocriptine or guanfacine.

detection across the neuronal population for intermediate target/ flanker distances.

\section{Could cholinergic modulation of visual spatial perceptual tuning arise from top-down attention effects?}

Another interpretation of our findings is that cholinergic enhancement influenced the spatial profile of target-flanker interactions by augmenting the effects of top-down spatial attention (Newman et al., 2012). Attention modulates center/surround interactions in neurons in macaque V4 (Sundberg et al., 2009) and MT (Anton-Erxleben et al., 2009), and top-down spatial attention itself has been proposed to have a center/surround spatial profile (Müller and Kleinschmidt, 2004; Müller et al., 2005a; Silver et al., 2007; Hopf et al., 2010).

Moreover, ACh is related to the effects of top-down attention. In rodents, levels of ACh release in prefrontal cortex track attentional effort, including increased demands in attention tasks caused by adding distractors (for review, see Sarter et al., 2005). In humans, donepezil increases the beneficial effects of top-down spatial attention on visual perception (Rokem et al., 2010). In addition, blockade of muscarinic ACh receptors eliminates attentional modulation of visual responses in macaque V1 (Herrero et al., 2008).

Improved visuospatial perceptual tuning through cholinergic modulation of attention would also account for our previous finding that cholinergic enhancement with donepezil decreased a 
behavioral measure of orientation-tuned surround suppression (Kosovicheva et al., 2012). Specifically, ACh may have increased attentional suppression of distractors (the flankers in the present study; the suppressive surround in Kosovicheva et al. (2012), thereby improving performance and perceptual spatial tuning. In this case, the facilitatory Gaussian in our model could be interpreted as enhanced performance due to suppression of distractors by top-down spatial attention.

Finally, we note that cholinergic effects on top-down attention and on spatial properties of visual RFs are not incompatible with one another. A gating mechanism for top-down attention in visual cortex could act in concert with $\mathrm{ACh}$ release to facilitate feedforward processing of stimuli at attended locations, increasing response amplitudes and decreasing excitatory RF size, thereby improving the spatial resolution of perception. In this context, it is notable that top-down spatial attention can modulate both excitatory RF size of V1 neurons (Roberts et al., 2007) and the spatial resolution of visual perception (Yeshurun et al., 2008) in an eccentricity-dependent manner. An exciting research direction for the future is to characterize the eccentricity dependence of cholinergic effects on physiological and perceptual spatial resolution and how these effects interact with attention and task demands.

\section{Models of dopaminergic and noradrenergic action in spatial tuning and visual attention}

Both the DA and NE systems have been implicated in attentional processes (for reviews, see Arnsten and Li, 2005; Aston-Jones and Cohen, 2005; Robbins and Arnsten, 2009; Noudoost and Moore, 2011b). However, in our study, the effects of cholinergic enhancement were fundamentally different from those of dopaminergic and noradrenergic enhancement, revealing a selective influence of ACh on visuospatial perception.

We enhanced dopaminergic activity through systemic administration of bromocriptine, a D2/D1 receptor agonist. We found no effect on overall task performance. In addition, although there was an interaction of drug and target-flanker distance for bromocriptine, this was not reflected in a systematic change in the DoG profile. These findings appear to contrast with previous neural studies in which both DA receptor agonists (Vijayraghavan et al., 2007) and antagonists (Williams and Goldman-Rakic, 1995) sharpened the tuning of spatially selective neurons in macaque prefrontal cortex during the delay period of a working memory task. In addition, Noudoost and Moore (2011a) found that DA receptor antagonists applied to the macaque frontal eye fields, a source of top-down attention signals to visual cortex (Moore and Armstrong, 2003), enhanced response amplitude and sharpened orientation tuning for neurons in cortical area V4.

However, these physiological effects were specific to D1 rather than D2 receptor modulations (Williams and Goldman-Rakic, 1995; Vijayraghavan et al., 2007; Noudoost and Moore, 2011a). Indeed, altering D2 receptor signaling either caused generalized suppression of responses (Williams and Goldman-Rakic, 1995) or influenced saccadic target selection but not visual tuning in V4 (Noudoost and Moore, 2011a). D1 and D2 receptors have different distributions in the brain (e.g., higher densities of D1 receptors in prefrontal cortex) and have been linked to distinct and sometimes even antagonistic cognitive effects (Cools and D’Esposito, 2011).

Bromocriptine has some binding affinity for both D1 and D2 receptors, although it binds $\sim 100$-fold more strongly to D2 receptors (Gerlach et al., 2003). Therefore, bromocriptine likely influenced both D1 and D2 receptor signaling in our study, but
D2 receptor effects may have been more pronounced. Given the studies cited above, a dominant effect of bromocriptine on D2 receptors would be consistent with the lack of perceptual tuning effects that we observed following bromocriptine administration. While previous studies have found that bromocriptine (via a combination of D2/D1 receptor activation) can influence a variety of top-down functions, such as cognitive control and working memory in humans (Kimberg et al., 2001; Gibbs and D'Esposito, 2005; Cools et al., 2007, 2009; Wallace et al., 2011; Stelzel et al., 2013; for review, see Cools and D'Esposito, 2011), our findings suggest that it does not substantially affect visuospatial perceptual tuning. More research is needed to establish how targeted modulation of D1 versus D2 receptors may influence visual perception in humans.

Noradrenergic activity is also thought to modulate attention via a prefrontal mechanism (Arnsten and Li, 2005; Aston-Jones and Cohen, 2005). We manipulated NE function with guanfacine, an $\alpha$-2a receptor agonist, which are found primarily on postsynaptic pyramidal neurons, suggesting that this is the primary site of their action (Arnsten and Li, 2005). These receptors have been associated with the beneficial effects of NE in prefrontal cortex, improving working memory performance in mice, rats, and monkeys, whereas blocking receptors creates symptoms of attention deficit hyperactivity disorder (ADHD) (for review, see Arnsten and Li, 2005). Systemic administration of guanfacine to healthy humans (Jäkälä et al., 1999), individuals with traumatic brain injury (McAllister et al., 2011), or individuals with ADHD (Hunt et al., 1995; Scahill et al., 2001) can lead to improved performance on a variety of cognitively demanding tasks (but see also lack of effects in Müller et al., 2005b; McAllister et al., 2011).

Despite these beneficial effects of NE on cognitive performance, we found that noradrenergic enhancement with guanfacine trended toward impairing target detection performance across all target-flanker distances. One possibility is that guanfacine does not strongly modulate lower-level visual attention tasks or target-flanker interactions in the absence of higher-level (e.g., working memory, cognitive control) cognitive demands or noradrenergic system disruption (e.g., in participants with ADHD, brain injury, or aging).

Finally, although all of the drugs used in our experiments have previously been shown to modulate human cognition, they have different mechanisms of action. We enhanced cholinergic processing by inhibiting acetylcholinesterase, the enzyme that breaks down ACh, thereby prolonging the actions of endogenously released ACh in a manner that is not selective for particular receptor subtypes. In contrast, our manipulations of the dopaminergic and noradrenergic systems were through agonists that tonically activate specific receptor subtypes. Therefore, the molecular mechanisms of action were not equivalent across the three pharmacological interventions used in this study, and the three drugs may have also varied in their influence on release of endogenous neurotransmitters through autoreceptor activation. These issues emphasize that the interpretation of systemic pharmacological manipulations in humans can be complex and suggest that complementing this research with more invasive manipulations in animal models will be very informative.

\section{Conclusion}

In conclusion, here we demonstrate that cholinergic enhancement with donepezil improves visuospatial perception in a manner consistent with sharpened perceptual tuning. These effects were selective: enhancement of the noradrenergic or dopaminer- 
gic systems did not improve visuospatial perception or alter its tuning. Our findings link the physiological and perceptual effects of ACh on visuospatial integration. Furthermore, they suggest a potential cholinergic mechanism for the effects of selective attention in visual cortex.

\section{References}

Angelucci A, Bressloff PC (2006) Contribution of feedforward, lateral and feedback connections to the classical receptive field center and extraclassical receptive field surround of primate V1. Prog Brain Res 154:93120. CrossRef Medline

Anton-Erxleben K, Carrasco M (2013) Attentional enhancement of spatial resolution: linking behavioural and neurophysiological evidence. Nat Rev Neurosci 14:188-200. CrossRef Medline

Anton-Erxleben K, Stephan VM, Treue S (2009) Attention reshapes centersurround receptive field structure in macaque cortical area MT. Cereb Cortex 19:2466-2478. CrossRef Medline

Arnold HM, Burk JA, Hodgson EM, Sarter M, Bruno JP (2002) Differential cortical acetylcholine release in rats performing a sustained attention task versus behavioral control tasks that do not explicitly tax attention. Neuroscience 114:451-460. CrossRef Medline

Arnsten AF, Li BM (2005) Neurobiology of executive functions: catecholamine influences on prefrontal cortical functions. Biol Psychiatry 57: 1377-1384. CrossRef Medline

Aston-Jones G, Cohen JD (2005) An integrative theory of locus coeruleusnorepinephrine function: adaptive gain and optimal performance. Annu Rev Neurosci 28:403-450. CrossRef Medline

Bentley P, Husain M, Dolan RJ (2004) Effects of cholinergic enhancement on visual stimulation, spatial attention, and spatial working memory. Neuron 41:969-982. CrossRef Medline

Bentley P, Driver J, Dolan RJ (2011) Cholinergic modulation of cognition: insights from human pharmacological functional neuroimaging. Prog Neurobiol 94:360-388. CrossRef Medline

Brainard DH (1997) The Psychophysics Toolbox. Spat Vis 10:433-436. CrossRef Medline

Cools R, D'Esposito M (2011) Inverted-U-shaped dopamine actions on human working memory and cognitive control. Biol Psychiatry 69:e113125. CrossRef Medline

Cools R, Sheridan M, Jacobs E, D'Esposito M (2007) Impulsive personality predicts dopamine-dependent changes in frontostriatal activity during component processes of working memory. J Neurosci 27:5506-5514. CrossRef Medline

Cools R, Frank MJ, Gibbs SE, Miyakawa A, Jagust W, D’Esposito M (2009) Striatal dopamine predicts outcome-specific reversal learning and its sensitivity to dopaminergic drug administration. J Neurosci 29:1538-1543. CrossRef Medline

Deleu D, Northway MG, Hanssens Y (2002) Clinical pharmacokinetic and pharmacodynamic properties of drugs used in the treatment of Parkinson's disease. Clin Pharmacokinet 41:261-309. CrossRef Medline

Disney AA, Aoki C, Hawken MJ (2007) Gain modulation by nicotine in macaque V1. Neuron 56:701-713. CrossRef Medline

Disney AA, Aoki C, Hawken MJ (2012) Cholinergic suppression of visual responses in primate V1 is mediated by GABAergic inhibition. J Neurophysiol 108:1907-1923. CrossRef Medline

Geisler WS, Albrecht DG (1997) Visual cortex neurons in monkeys and cats: detection, discrimination, and identification. Vis Neurosci 14:897-919. CrossRef Medline

Gerlach M, Double K, Arzberger T, Leblhuber F, Tatschner T, Riederer P (2003) Dopamine receptor agonists in current clinical use: comparative dopamine receptor binding profiles defined in the human striatum. J Neural Transm (Vienna) 110:1119-1127. CrossRef Medline

Gibbs SE, D'Esposito M (2005) A functional MRI study of the effects of bromocriptine, a dopamine receptor agonist, on component processes of working memory. Psychopharmacology 180:644-653. CrossRef Medline

Gil Z, Connors BW, Amitai Y (1997) Differential regulation of neocortical synapses by neuromodulators and activity. Neuron 19:679-686. CrossRef Medline

Giocomo LM, Hasselmo ME (2007) Neuromodulation by glutamate and acetylcholine can change circuit dynamics by regulating the relative influence of afferent input and excitatory feedback. Mol Neurobiol 36:184200. CrossRef Medline

Hasselmo ME, Sarter M (2011) Modes and models of forebrain cholinergic neuromodulation of cognition. Neuropsychopharmacology 36:52-73. CrossRef Medline

Herrero JL, Roberts MJ, Delicato LS, Gieselmann MA, Dayan P, Thiele A (2008) Acetylcholine contributes through muscarinic receptors to attentional modulation in V1. Nature 454:1110-1114. CrossRef Medline

Hopf JM, Boehler CN, Schoenfeld MA, Heinze HJ, Tsotsos JK (2010) The spatial profile of the focus of attention in visual search: insights from MEG recordings. Vision Res 50:1312-1320. CrossRef Medline

Hunt RD, Arnsten AF, Asbell MD (1995) An open trial of guanfacine in the treatment of attention-deficit hyperactivity disorder. J Am Acad Child Adolesc Psychiatry 34:50-54. CrossRef Medline

Jäkälä P, Riekkinen M, Sirviö J, Koivisto E, Kejonen K, Vanhanen M, Riekkinen P Jr (1999) Guanfacine, but not clonidine, improves planning and working memory performance in humans. Neuropsychopharmacology 20:460 - 470. CrossRef Medline

Kimberg DY, Aguirre GK, Lease J, D’Esposito M (2001) Cortical effects of bromocriptine, a D-2 dopamine receptor agonist, in human subjects, revealed by fMRI. Hum Brain Mapp 12:246-257. CrossRef Medline

Kimura F, Fukuda M, Tsumoto T (1999) Acetylcholine suppresses the spread of excitation in the visual cortex revealed by optical recording: possible differential effect depending on the source of input. Eur J Neurosci 11:3597-3609. CrossRef Medline

Kleiner M, Brainard D, Pelli D, Ingling A, Murray R, Broussard C (2007) What's new in Psychtoolbox-3? Perception 36:1-16.

Kosovicheva AA, Sheremata SL, Rokem A, Landau AN, Silver MA (2012) Cholinergic enhancement reduces orientation-specific surround suppression but not visual crowding. Front Behav Neurosci 6:61. CrossRef Medline

McAllister TW, McDonald BC, Flashman LA, Ferrell RB, Tosteson TD, Yanofsky NN, Grove MR, Saykin AJ (2011) Alpha-2 adrenergic challenge with guanfacine one month after mild traumatic brain injury: altered working memory and BOLD response. Int J Psychophysiol 82: 107-114. CrossRef Medline

Moore T, Armstrong KM (2003) Selective gating of visual signals by microstimulation of frontal cortex. Nature 421:370-373. CrossRef Medline

Mosqueda-Garcia R (1990) Guanfacine: a second generation alpha 2-adrenergic blocker. Am J Med Sci 299:73-76. CrossRef Medline

Muir JL, Dunnett SB, Robbins TW, Everitt BJ (1992) Attentional functions of the forebrain cholinergic systems: effects of intraventricular hemicholinium, physostigmine, basal forebrain lesions and intracortical grafts on a multiple-choice serial reaction time task. Exp Brain Res 89:611-622. Medline

Müller NG, Kleinschmidt A (2004) The attentional 'spotlight's' penumbra: center-surround modulation in striate cortex. Neuroreport 15:977-980. CrossRef Medline

Müller NG, Mollenhauer M, Rösler A, Kleinschmidt A (2005a) The attentional field has a Mexican hat distribution. Vision Res 45:1129-1137. CrossRef Medline

Müller U, Clark L, Lam ML, Moore RM, Murphy CL, Richmond NK, Sandhu RS, Wilkins IA, Menon DK, Sahakian BJ, Robbins TW (2005b) Lack of effects of guanfacine on executive and memory functions in healthy male volunteers. Psychopharmacology 182:205-213. CrossRef Medline

Newman EL, Gupta K, Climer JR, Monaghan CK, Hasselmo ME (2012) Cholinergic modulation of cognitive processing: insights drawn from computational models. Front Behav Neurosci 6:24. CrossRef Medline

Noudoost B, Moore T (2011a) Control of visual cortical signals by prefrontal dopamine. Nature 474:372-375. CrossRef Medline

Noudoost B, Moore T (2011b) The role of neuromodulators in selective attention. Trends Cogn Sci 15:585-591. CrossRef Medline

Nurminen L, Angelucci A (2014) Multiple components of surround modulation in primary visual cortex: multiple neural circuits with multiple functions? Vision Res 104:47-56. CrossRef Medline

Nurminen L, Kilpeläinen M, Laurinen P, Vanni S (2009) Area summation in human visual system: psychophysics, fMRI, and modeling. J Neurophysiol 102:2900-2909. CrossRef Medline

Passetti F, Dalley JW, O'Connell MT, Everitt BJ, Robbins TW (2000) Increased acetylcholine release in the rat medial prefrontal cortex during performance of a visual attentional task. Eur J Neurosci 12:3051-3058. CrossRef Medline

Pelli DG (1997) The VideoToolbox software for visual psychophysics: transforming numbers into movies. Spat Vis 10:437-442. CrossRef Medline

Polat U, Sagi D (1993) Lateral interactions between spatial channels: sup- 
pression and facilitation revealed by lateral masking experiments. Vision Res 33:993-999. CrossRef Medline

Robbins TW, Arnsten AF (2009) The neuropsychopharmacology of frontoexecutive function: monoaminergic modulation. Annu Rev Neurosci 32: 267-287. CrossRef Medline

Robbins TW, Everitt BJ, Marston HM, Wilkinson J, Jones GH, Page KJ (1989) Comparative effects of ibotenic acid- and quisqualic acidinduced lesions of the substantia innominata on attentional function in the rat: further implications for the role of the cholinergic neurons of the nucleus basalis in cognitive processes. Behav Brain Res 35:221-240. CrossRef Medline

Roberts MJ, Zinke W, Guo K, Robertson R, McDonald JS, Thiele A (2005) Acetylcholine dynamically controls spatial integration in marmoset primary visual cortex. J Neurophysiol 93:2062-2072. CrossRef Medline

Roberts M, Delicato LS, Herrero J, Gieselmann MA, Thiele A (2007) Attention alters spatial integration in macaque $\mathrm{V} 1$ in an eccentricity-dependent manner. Nat Neurosci 10:1483-1491. CrossRef Medline

Rogers SL, Friedhoff LT (1998) Pharmacokinetic and pharmacodynamic profile of donepezil $\mathrm{HCl}$ following single oral doses. Br J Clin Pharmacol 46 [Suppl 1]:1-6.

Rokem A, Landau AN, Garg D, Prinzmetal W, Silver MA (2010) Cholinergic enhancement increases the effects of voluntary attention but does not affect involuntary attention. Neuropsychopharmacology 35:25382544. CrossRef Medline

Rokem A, Landau AN, Prinzmetal W, Wallace DL, Silver MA, D’Esposito M (2012) Modulation of inhibition of return by the dopamine D2 receptor agonist bromocriptine depends on individual DAT1 genotype. Cereb Cortex 22:1133-1138. CrossRef Medline

Sarter M, Hasselmo ME, Bruno JP, Givens B (2005) Unraveling the attentional functions of cortical cholinergic inputs: interactions between signal-driven and cognitive modulation of signal detection. Brain Res Rev 48:98-111. CrossRef Medline

Scahill L, Chappell PB, Kim YS, Schultz RT, Katsovich L, Shepherd E, Arnsten AF, Cohen DJ, Leckman JF (2001) A placebo-controlled study of guanfacine in the treatment of children with tic disorders and atten- tion deficit hyperactivity disorder. Am J Psychiatry 158:1067-1074. CrossRef Medline

Silver MA, Ress D, Heeger DJ (2007) Neural correlates of sustained spatial attention in human early visual cortex. J Neurophysiol 97:229-237. CrossRef Medline

Silver MA, Shenhav A, D’Esposito M (2008) Cholinergic enhancement reduces spatial spread of visual responses in human early visual cortex. Neuron 60:904-914. CrossRef Medline

Stelzel C, Fiebach CJ, Cools R, Tafazoli S, D’Esposito M (2013) Dissociable fronto-striatal effects of dopamine D2 receptor stimulation on cognitive versus motor flexibility. Cortex 49:2799-2811. CrossRef Medline

Sundberg KA, Mitchell JF, Reynolds JH (2009) Spatial attention modulates center-surround interactions in macaque visual area V4. Neuron 61:952963. CrossRef Medline

Thiele A (2013) Muscarinic signaling in the brain. Annu Rev Neurosci 36: 271-294. CrossRef Medline

Vijayraghavan S, Wang M, Birnbaum SG, Williams GV, Arnsten AF (2007) Inverted- $\mathrm{U}$ dopamine $\mathrm{D} 1$ receptor actions on prefrontal neurons engaged in working memory. Nat Neurosci 10:376-384. CrossRef Medline

Wallace DL, Vytlacil JJ, Nomura EM, Gibbs SE, D'Esposito M (2011) The dopamine agonist bromocriptine differentially affects fronto-striatal functional connectivity during working memory. Front Hum Neurosci 5:32. CrossRef Medline

Watson AB, Pelli DG (1983) Quest: a Bayesian adaptive psychometric method. Percept Psychophys 33:113-120. CrossRef Medline

Williams GV, Goldman-Rakic PS (1995) Modulation of memory fields by dopamine D1 receptors in prefrontal cortex. Nature 376:572-575. CrossRef Medline

Yeshurun Y, Montagna B, Carrasco M (2008) On the flexibility of sustained attention and its effects on a texture segmentation task. Vision Res 48: 80-95. CrossRef Medline

Yu C, Levi DM (1997) Spatial facilitation predicted with end-stopped spatial filters. Vision Res 22:3117-3127. CrossRef Medline 